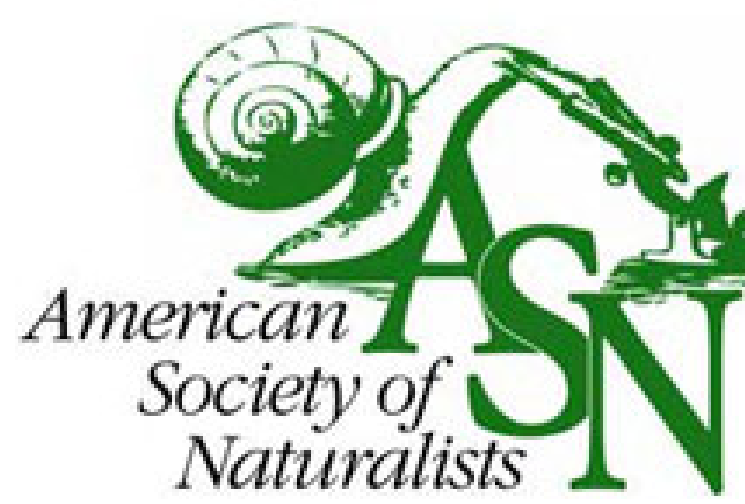

Density-Dependent Sex Ratio Adjustment and the Allee Effect: A Model and a Test Using a Sex-Changing Fish.

Author(s): Stefan P. W. Walker, Loïc Thibaut, Mark I. McCormick

Source: The American Naturalist, Vol. 176, No. 3 (September 2010), pp. 312-321

Published by: The University of Chicago Press for The American Society of Naturalists

Stable URL: http://www.jstor.org/stable/10.1086/655219

Accessed: 13/01/2011 00:29

Your use of the JSTOR archive indicates your acceptance of JSTOR's Terms and Conditions of Use, available at http://www.jstor.org/page/info/about/policies/terms.jsp. JSTOR's Terms and Conditions of Use provides, in part, that unless you have obtained prior permission, you may not download an entire issue of a journal or multiple copies of articles, and you may use content in the JSTOR archive only for your personal, non-commercial use.

Please contact the publisher regarding any further use of this work. Publisher contact information may be obtained at http://www.jstor.org/action/showPublisher?publisherCode=ucpress.

Each copy of any part of a JSTOR transmission must contain the same copyright notice that appears on the screen or printed page of such transmission.

JSTOR is a not-for-profit service that helps scholars, researchers, and students discover, use, and build upon a wide range of content in a trusted digital archive. We use information technology and tools to increase productivity and facilitate new forms of scholarship. For more information about JSTOR, please contact support@ jstor.org. 


\title{
Density-Dependent Sex Ratio Adjustment and the Allee Effect: A Model and a Test Using a Sex-Changing Fish
}

\author{
Stefan P. W. Walker, ${ }^{\star}$ Loïc Thibaut, and Mark I. McCormick
}

School of Marine and Tropical Biology and the Australian Research Council Centre of Excellence for Coral Reef Studies, James Cook University, Townsville, Queensland 4812, Australia

Submitted April 8, 2010; Accepted April 26, 2010; Electronically published July 12, 2010

\begin{abstract}
Positive density dependence (i.e., the Allee effect; AE) often has important implications for the dynamics and conservation of populations. Here, we show that density-dependent sex ratio adjustment in response to sexual selection may be a common AE mechanism. Specifically, using an analytical model we show that an AE is expected whenever one sex is more fecund than the other and sex ratio bias toward the less fecund sex increases with density. We illustrate the robustness of this pattern, using Monte Carlo simulations, against a range of body size-fecundity relationships and sexallocation strategies. Finally, we test the model using the sex-changing polygynous reef fish Parapercis cylindrica; positive density dependence in the strength of sexual selection for male size is evidenced as the causal mechanism driving local sex ratio adjustment, hence the AE. Model application may extend to invertebrates, reptiles, birds, and mammals, in addition to over 70 reef fishes. We suggest that protected areas may often outperform harvest quotas as a conservation tool since the latter promotes population fragmentation, reduced polygyny, a balancing of the sex ratio, and hence up to a $50 \%$ decline in per capita fecundity, while the former maximizes polygyny and source-sink potential.
\end{abstract}

Keywords: positive density dependence, polygyny, sexual selection, sex ratio adjustment, protogynous hermaphrodite, reef fish.

\section{Introduction}

An Allee effect occurs when some component of per capita fitness deteriorates as population density or size decreases toward zero, resulting in a positive density-dependent relationship (Allee 1931; Stephens et al. 1999). A number of mechanisms have been proposed to drive the Allee effect, such as reduced predator vigilance, reduced care for young, or reduced foraging efficiency at low population sizes or densities (Sæther et al. 1996; Courchamp et al. 1999; Stephens and Sutherland 1999). However, the reduced probability of finding mates in small sexually reproducing populations is thought to be the most common

* Corresponding author; e-mail: stefan.walker@jcu.edu.au.

Am. Nat. 2010. Vol. 176, pp. 312-321. (C) 2010 by The University of Chicago. 0003-0147/2010/17603-52068\$15.00. All rights reserved.

DOI: $10.1086 / 655219$ mechanism (Ehrlich and Roughgarden 1987; Levitan et al. 1992; Groom 1998; Kindvall et al. 1998; Wells et al. 1998; Berec et al. 2001; Davis et al. 2004). An Allee effect in some component of fitness can result in a decline in per capita population growth rate at a small population density or size (i.e., a demographic Allee effect, also referred to as depensation and inverse density dependence; Stephens et al. 1999; Courchamp et al. 2008), and if population growth rate becomes negative, there will be a critical population density or size below which the population slides to extinction (Courchamp et al. 1999, 2008). Hence, unlike negative density-dependent processes, which tend to stabilize population dynamics, Allee effects tend to drive erratic population behavior, whereby populations either boom (when above the critical density threshold) or bust (when below the critical population density threshold). Consequently, knowledge of potential Allee effect mechanisms is a key component to understanding the dynamics of groups, populations, and communities and a prerequisite to strategic conservation efforts (Myers et al. 1995; Leirmann and Hilborn 1997; Courchamp et al. 1999, 2008; Stephens and Sutherland 1999; Hutchings 2000; De Roos and Persson 2002; Morris 2002).

One potentially widespread Allee effect mechanism that has yet to receive attention is density-dependent sex ratio adjustment. Sex ratio adjustment in response to local selection pressures is a common feature of many plant and animal populations and represents some of the strongest evidence in support of Darwin's theory of natural selection (Hamilton 1969; Trivers and Willard 1973; Werren 1980; Charnov 1982; West et al. 2000; Wade et al. 2003; Reece et al. 2008). An initially positive relationship between population density and per capita fecundity (PCF) should be expected whenever one sex can produce more offspring than the other and sex ratio bias toward the less fecund sex increases with population density (see "The Model"). This is because, as density increases, the reproductive capacity of the more fecund sex is better exploited and, therefore, more offspring per individual can be produced. Importantly, however, unlike Allee effects described to 
date, which place emphasis on density-dependent individual female fitness, the sex ratio-based Allee effect involves a density-dependent increase in individual fitness in the more fecund sex only.

In sexually reproducing organisms, males are typically more fecund than females. Indeed, polygynous mating systems are frequent in nature, wherein a few dominant males monopolize the reproductive efforts of several females. In such species, any mechanism that selects for a positively density-dependent reduction in the proportion of male mating group members from an equal sex ratio can potentially drive a fecundity Allee effect (see "The Model"). Theoretical and empirical evidence suggests that sexual selection for large or high-quality males within polygynous groups may provide such a mechanism. For example, for separate-sex species (gonochores) it has been argued that under strong sexual selection for male size or quality, females should be selected to produce fewer sons as density increases, resources become limited, and maternal condition declines (Trivers and Willard 1973; see also Wade et al. 2003). This is because females in poor condition produce poor-quality sons, and poor-quality sons will have little prospect of realizing their fecundity potential in the presence of strong sexual selection (Trivers and Willard 1973). For hermaphrodites, moreover, it has been shown that if large individuals can monopolize the male reproductive role, then there is a clear advantage to allocating most or all reproductive effort to female function when small and later allocating most or all reproductive effort to male function when a competitive size is reached (see the size-advantage hypothesis [SAH] for protogynous hermaphroditism; Ghiselin 1969; Warner 1975, 1988; Munday et al. 2006). It follows that with a positively densitydependent increase in the strength of sexual selection for large male size, there should be an increase in female function among smaller individuals (Warner 1975, 1984a, 1984b, 1988; Petersen and Fischer 1986; Lutnesky 1994; Walker and McCormick 2009).

While protogynous hermaphroditism (sex change from female to male) is not an essential proximate feature of density-dependent sex ratio adjustment and the Allee effect (see "The Model"), sex-changers are, for a number of reasons, an important and ideal model for examining it. First, the vast number of sex-changers (thousands), coupled with their taxonomic extent (annelids, mollusks, crustaceans, and fish), warrants attention. Protogynous sex change is in fact the norm for a number of ecologically and economically important reef fish families, including Labridae, Scaridae, Serranidae, Pomacanthidae, Pomacentridae, and Pinguipididae (Thresher 1984; Sadovy de Mitcheson and Liu 2008). Second, sex-change induction typically involves a strong environmental component, whereby local social or demographic conditions influence how many individ- uals change sex, which individuals change sex, and the timing of their sexual transition (Robertson 1972; Shapiro 1984; Ross 1990; Lutnesky 1994; Walker and McCormick 2009). Finally, many sex-changers are site attached and ecologically or energetically restricted in their use of space, such that population density directly influences the potential for polygynous mating groups to form and the degree of polygyny (e.g., hawkfishes: Donaldson 1989, 1990; angelfishes: Moyer 1990; butterflyfishes: Hourigan 1989; groupers: Shpigel and Fishelson 1991; triggerfishes: Fricke 1980; Ishihara and Kuwamura 1996). Together, these points suggest that local sex ratio adjustment in response to density-dependent sexual selection may provide a mechanistic explanation for depensation in many marine populations and communities (see also Paddack et al. 2009).

Here, we develop analytical and Monte Carlo models with which to examine the nature of density-dependent per capita fecundity under a range of sex-allocation strategies and body size-fecundity relationships. We then test the model empirically using the polygynous sex-changing reef fish Parapercis cylindrica. We discuss the likely extent of Allee effects associated with density-dependent sex ratio adjustment among tropical reef fishes and more generally the implications of density-dependent sex ratio adjustment in response to sexual selection for the dynamics, conservation, and management of polygynous species.

\section{The Model}

Consider a patchy environment that supports varying group sizes (GSs), and let us say that the male is more fecund than the female. A fecundity Allee effect will occur whenever sex ratio bias (from $1: 1$ ) toward the less fecund sex (in this case, the female) increases with population density and GS (i.e., GS increases with density, and there are a fixed number of males per group). Most simply put, if we initially assume that there is only ever one male per group, that all females have equal fecundity (FF), and that all their eggs are fertilized, the initial increase in per capita fecundity (PCF) with GS may be expressed as

$$
\mathrm{PCF}=\mathrm{FF}\left[\frac{(\mathrm{GS}-1)}{\mathrm{GS}}\right]
$$

or

$$
\mathrm{PCF}=\mathrm{FF}\left(1-\frac{1}{\mathrm{GS}}\right)
$$

Essentially, $\mathrm{PCF}=1 / 2(\mathrm{FF})$, when GS $=2$ (monogamy), and approaches FF hyperbolically with a further increase 
in GS (i.e., with an increase in polygyny; fig. $1 A$ ). However, PCF will cease to increase with GS once the male fertility threshold $\left(M_{\max }\right)$ is reached, after which point not all the eggs from all females can be fertilized (because of sperm depletion), and, therefore, PCF will decrease with GS hyperbolically (fig. 1A):

$$
\mathrm{PCF}=\frac{M_{\max }}{\mathrm{GS}} .
$$

The complete representation for PCF in response to GS is thus

$$
\mathrm{PCF}=\min \left[\frac{M_{\max }}{\mathrm{GS}}, \frac{\mathrm{FF}(\mathrm{GS}-1)}{\mathrm{GS}}\right]
$$

Simply put, PCF at GS is determined by the limiting factor: either male fecundity or the number of females in the group (fig. 1A). Additional factors that may affect PCF, such as fertilization success $\left(p_{\mathrm{f}}\right)$, hatching success $\left(p_{\mathrm{h}}\right)$, and settlement success $\left(p_{s}\right)$, can be incorporated as multiplicative probabilities:

$$
\mathrm{PCF}=p_{\mathrm{s}} p_{\mathrm{h}} p_{\mathrm{f}} \min \left[\frac{M_{\mathrm{max}}}{\mathrm{GS}}, \frac{\mathrm{FF}(\mathrm{GS}-1)}{\mathrm{GS}}\right]
$$

When these probabilities $\left(p_{\mathrm{s}}, p_{\mathrm{h}}\right.$, and $\left.p_{\mathrm{f}}\right)$ are not density dependent, the general pattern of the Allee effect will be preserved (fig. $1 B$ ). However, if these probabilities are dependent on density and group size such that increased group size decreases the likelihood of fertilization success, hatching, or settlement, then the Allee effect will be reduced.

This analytical model (AM) relies on the assumptions that all individuals are equivalent, FF is constant, and the male is randomly chosen. While these assumptions are unlikely to be met in nature (e.g., Lutnesky and Kosaki 1995; Walker and McCormick 2009), the AM will be useful for examining the amount of variation in PCF as a function of GS because of the sex ratio effect only.

The female body size-fecundity relationship and the details of the sex-allocation strategy influence the shape and magnitude of the PCF versus GS relationship, yet the pattern of initially increasing PCF with GS is robust. To illustrate this point, we employed a set of Monte Carlo (MC) models that were programmed in R (R Development Core Team 2009). For each MC model, using the same body size distribution, we specified a particular female body size-fecundity relationship $\left(\mathrm{FF}_{\mathrm{b}}\right)$ and sex-allocation strategy (SA) combination. The $\mathrm{FF}_{\mathrm{b}}$ categories were positively linear $\left(\mathrm{FF}_{\mathrm{bL}}\right.$; fig. $\left.2 \mathrm{~A}, \mathrm{i}\right)$, a power curve for which mean female fecundity for 100 randomly drawn individ-

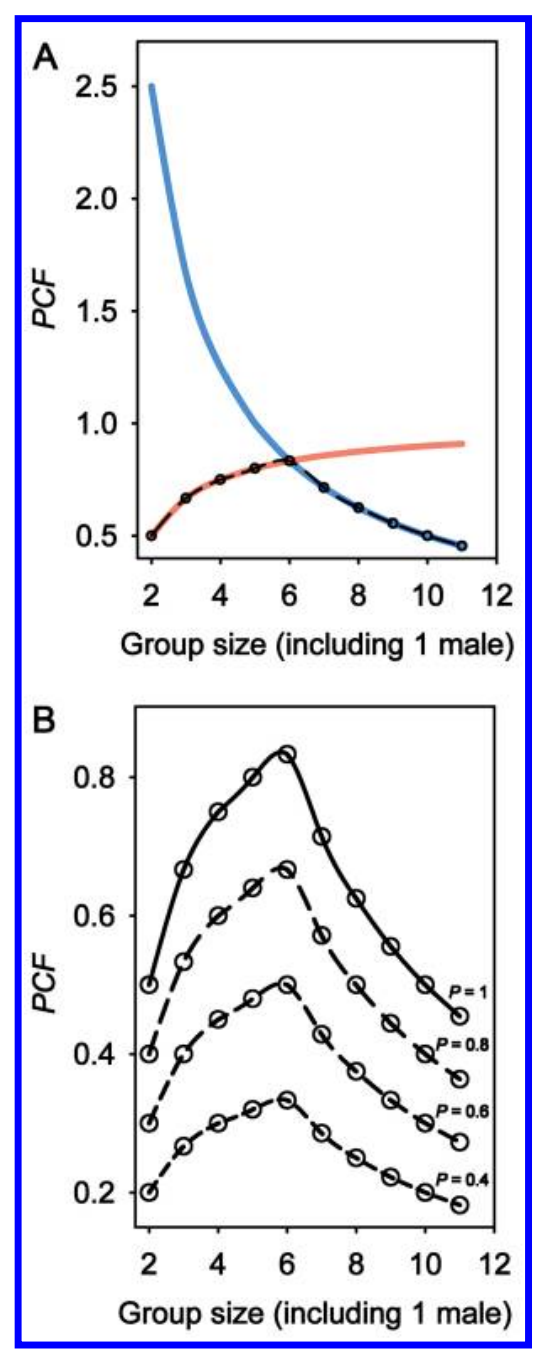

Figure 1: $A$, Analytical model components (eq. [2]) where the female : male potential fecundity ratio $=1: 5$ and $p_{\mathrm{s}} p_{\mathrm{h}} p_{\mathrm{f}}=P=1$. Red line, female per capita fecundity component; blue line, male potential fecundity-depletion component (in response to the number of females). $B$, Solved analytical model trajectories for per capita fecundity (PCF) where the female: male potential fecundity ratio $=1: 5$ and $P$ ranges from 1 to 4 .

uals is similar to the mean female fecundity of 100 randomly drawn individuals with body size-fecundity relationship $\mathrm{FF}_{\mathrm{bL}}\left(\mathrm{FF}_{\mathrm{bPl}}\right.$; fig. $\left.2 \mathrm{~B}, \mathrm{i}\right)$, and a power curve for which maximum female fecundity for 100 randomly drawn individuals is similar to the maximum female fecundity of 100 randomly drawn individuals with body size-fecundity relationship $\mathrm{FF}_{\mathrm{bL}}\left(\mathrm{FF}_{\mathrm{bP} 2}\right.$; fig. $2 C$, $i$ ). The sexallocation strategies were male is the largest group member, male is the smallest group member, and male is randomly allocated. For each $\mathrm{FF}_{\mathrm{b}}$-SA combination, the Monte Carlo procedure involved randomly selecting individuals from 


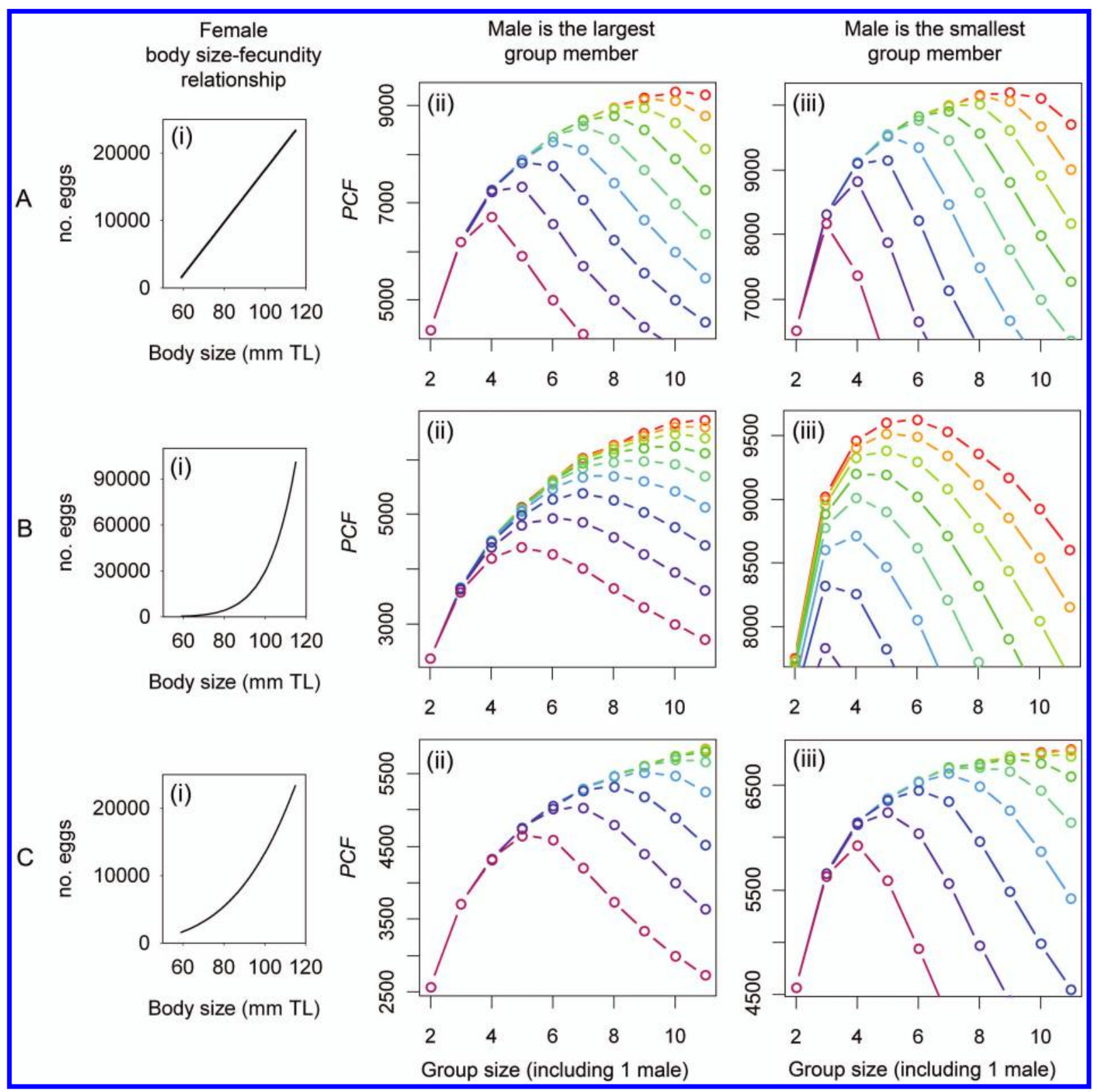

Figure 2: Monte Carlo model; relationships between group size and per capita fecundity (PCF) for a range of female body size-fecundity functions (i), size-based sex-allocation strategies (ii, iii), and maximum male fecundities (colored lines). Each line color represents the same male fecundity value across panels. All simulations were run using the same body size distribution. TL $=$ total length.

the same body size distribution, allocating them among a group size distribution, and then assigning one group member as the male (on the basis of the particular SA strategy). The remaining female group members were then assigned their fecundity values on the basis of each female's body size and the particular $\mathrm{FF}_{\mathrm{b}}$ relationship. PCF for each group was then calculated for a range of male fecundity values. This whole procedure was repeated for each $\mathrm{FF}_{\mathrm{b}}$ -
SA combination 1,000 times, and the average PCF versus GS profiles were plotted (fig. 2).

The MC model predicts the difference in PCF as a function of GS to be greatest when the male is the largest group member and $\mathrm{FF}_{\mathrm{b}}$ is positively linear. However, PCF for any given GS is predicted to be greater when the male is the smallest group member, intermediate when the male is chosen randomly, and lowest when the male is the largest 
group member (fig. 3). In addition, for any given SA, a shift from a linear $\mathrm{FF}_{\mathrm{b}}\left(\mathrm{FF}_{\mathrm{bL}}\right)$ to the power-curve $\mathrm{FF}_{\mathrm{bP1}}$ and finally to the power-curve $\mathrm{FF}_{\mathrm{bP} 2}$ tends to reduce maximum PCF and variation in PCF (figs. 2, 3).

\section{Test of the Model Using a Polygynous Sex-Changing Fish}

We used data on the haremic reef fish Parapercis cylindrica (family Pinguipedidae) collected within the lagoon of Lizard Island, Great Barrier Reef $\left(14^{\circ} 40.9^{\prime} \mathrm{S}, 145^{\circ} 26.8^{\prime} \mathrm{E}\right)$ to test the predictions of the size-advantage model for protogynous sex change and to examine whether the analytical model (which is insensitive to the protogynous sex-change rule) or the Monte Carlo model (which incorporates the protogynous sex-change rule) better explains the relationship between GS and PCF. Parapercis cylindrica is a shortlived fish that occupies a macroalgae and coral rubble habitat within sheltered tropical waters (Randall et al. 1997). Each female defends a permanent all-purpose territory in which it feeds, spawns, and seeks shelter, and males form harems by defending several neighboring females (Stroud 1982; Walker and McCormick 2009). Each day during sunset, the male pelagic spawns with each ripe female in his harem. Spawning activity peaks for several days around each new and full moon (S. P. W. Walker, unpublished data). Males are derived exclusively from females (sequential monandric protogyny) and can be identified by coloration (Stroud 1982; Walker and McCormick 2004, 2009; Frisch et al. 2007).

Social group composition was first determined by observing the coloration and behavior of individual fish in the wild $(n=232)$ and by mapping their territories. This was carried out at six sites within the lagoon of Lizard Island. Before observations, a $30 \times 50-\mathrm{m}$ reference grid at $5-\mathrm{m}^{2}$ resolution was laid over the substrate to aid in the tracking of individuals and to estimate subpopulation density. One 15-min observation was made on each individual. A 15-min observation time has been shown to give an accurate estimate of individual territory location and size (Walker and McCormick 2009). Females ( $n=$ $177)$ were assigned to the male $(n=55)$ whose territory encompassed the particular female. After the determination of group composition, all individuals were collected with a clove oil anesthetic and a hand net and measured with calipers ( $\mathrm{mm}$ total length; TL).

To establish the size-based egg production rate, we collected 125 females from randomly located social groups within the Lizard Island lagoon. All individuals were collected within the hour before spawning. These individuals were anesthetized with clove oil and measured (mm TL), and their eggs were stripped and stored in 70\% ethanol for counting in the laboratory. We analyzed the relation-

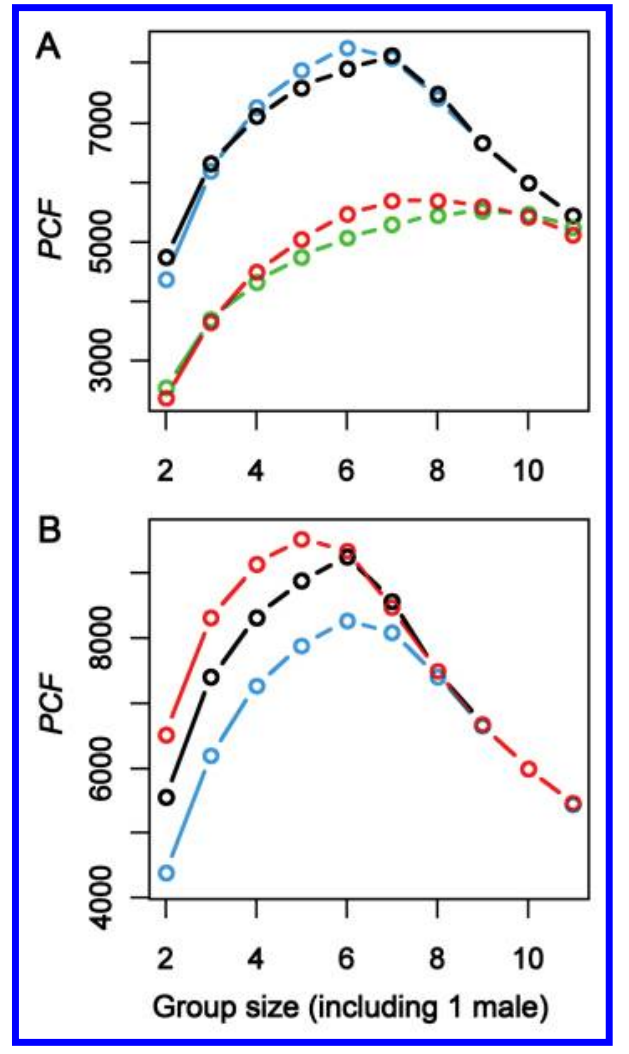

Figure 3: Monte Carlo model with analytical model (eq. [1]) comparison. $A$, Differences in the group size (GS) versus per capita fecundity (PCF) relationship for a range of female body size-fecundity functions $\left(\mathrm{FF}_{\mathrm{b}}\right)$ using the same body size distribution, with sex-allocation strategy (male is the largest group member) and male fecundity held constant $(60,000$ eggs). Black, analytical model where female fecundity $=\mathrm{FF}_{\mathrm{AM}}$; blue, Monte Carlo model with linear female body size-fecundity relationship $\mathrm{FF}_{\mathrm{bL}}$ (i.e., fig. $2 A, i$ ); red, Monte Carlo model with the power-curve female body size-egg production relationship $\mathrm{FF}_{\mathrm{bP} 1}$ (i.e., fig. $2 B$, i); green, Monte Carlo model with the power-curve female body size-egg production relationship $\mathrm{FF}_{\mathrm{bP} 2}$ (i.e., fig. $2 C$, i). $B$, Effect of sex-allocation strategy on PCF in relation to GS with male fecundity (60,000 eggs) and the female body size-fecundity relationship $\left(\mathrm{FF}_{\mathrm{bL}}\right)$ held constant. Blue, male is the largest group member; red, male is the smallest group member; black, male group member is randomly assigned in relation to body size rank. All simulations were run using the same body size distribution.

ship between body size and daily egg production using an ordinary least squares (OLS) regression.

To determine the maximum female monthly spawning frequency, we created 20 experimental patch reefs in the lagoon of Lizard Island, using a generous quantity of coral rubble and macroalgae habitat. Each patch reef was recruited with an adult female and male, with the entire female size distribution being used among the 20 patches. Experimental fishes were captured randomly from several adjacent subpopulations, and experimental pairs were created such that each individual had never interacted before 
the experiment. After an acclimation period (5-7 days), experimental pairs were observed each day to determine monthly spawning frequency. The relationship between female body size and monthly spawning frequency was analyzed using an OLS regression.

Monthly spawning frequencies and fertilization rates were investigated among a subset of natural social groups within the lagoon of Lizard Island $(n=7)$. At the beginning of each sampling period, all individuals from social groups were captured using a clove oil anesthetic and a hand net, measured (mm TL), visually sexed, and tagged using a subcutaneous tattoo for individual recognition (Northwest Marine). A reference grid at $5 \times 5-\mathrm{m}$ resolution was placed over the substrate to aid in the tracking and relocation of individuals. Each afternoon, the male was continuously observed, to record the number of spawns and the spawning participants. The relationship between group size and descending mean female spawning frequency (FSF) was analyzed using the hyperbolic regression function FSF $=a b /(a+x)$, where $x$ is group size (including the male) and $a$ and $b$ are constants.

Consecutive pair spawn clouds from the tracked subset of social groups $(n=7)$ were collected in separate $50-\mathrm{L}$ plastic bags to determine fertilization rate. Spawn clouds were captured $10 \mathrm{~s}$ after gamete release and incubated in situ for approximately $2 \mathrm{~h}$ with constant air supply and an external-flowing seawater bath (Shapiro et al. 1994; Marconato et al. 1995, 1997; Warner et al. 1995). The water sample was then filtered to isolate eggs, and eggs were scored as fertilized or unfertilized on the basis of the presence or absence of cell division, respectively. We analyzed the relationship between GS and fertilization rate using an OLS regression.

We estimated group size-dependent per capita fecundity (PCF; at the monthly scale) among the broader distribution of social groups in the wild $(n=55$ social groups) by (1) correcting individual female body sizes for daily egg production using the body size by egg production function, (2) multiplying daily egg production by group size-specific female monthly spawning frequency and group size-specific fertilization rate, (3) adding the individual monthly fecundity estimates for females within each group, and (4) dividing the total monthly fecundity for each group by total group size (including the male). We parameterized the Monte Carlo model by randomly selecting from the pool of 232 individuals found among natural social groups at Lizard Island and combining them into groups on the basis of the observed group size range (2-11). We then assigned the largest individual within each group to "male" and corrected the body size of remaining individuals (females) for monthly fecundity using the body size ( $\mathrm{mm}$ TL) versus daily egg production relationship observed at
Lizard Island (eggs day ${ }^{-1}=37.334 \mathrm{TL}-2,053 ; r^{2}=0.3$; $\left.F_{1,123}=43.6, P<.01\right)$, the monthly spawning frequency of experimental monogamous females observed at Lizard Island (i.e., the assumed maximum female monthly spawning rate: $10.42 \pm 3.8 \mathrm{SE}$; female $n=20$ ), and the group size (including the male)-specific fertilization rate observed at Lizard Island $(\mathrm{FR}=-0.0033 \mathrm{GS}+0.9847$; $r^{2}=0.3 ; F_{1,12}=5.18, P=.042$; mean FR range: $96.1 \%-$ $98 \%)$. We then divided the sum of monthly fecundity for females within each group by total group size (including the male) and calculated expected PCF in relation to GS for a range of $M_{\max }$ values (which defines the peak in PCF and the point preceding hyperbolic decline in PCF). This whole procedure was repeated 10,000 times for each value of $M_{\max }$. Finally, we fitted the observed GS versus PCF data to the Monte Carlo model by finding the value of $M_{\max }$ that minimized the sum of squares (SS) using numerical optimization (function “optimize()" in R).

To parameterize the analytical model (eq. [2]), we took the average female body size found in the Lizard Island sample and corrected it for female monthly fecundity (FF) using the same egg production, monthly spawning frequency, and fertilization rate functions used in the Monte Carlo model. We then calculated PCF in relation to GS for a range of $M_{\max }$ values. Finally, we fitted the observed GS versus PCF data to the analytical model by finding the value of $M_{\max }$ that minimized SS using numerical optimization (as above).

\section{Results and Discussion}

Among the six sites surveyed, a positive relationship was observed between subpopulation density (individuals/100 $\mathrm{m}^{2}$ ) and mean haremic group size (mean GS = population density $(0.5)+1.7 ; r^{2}=0.84 ; F_{1,4}=21.69, P<.001 ;$ fig.

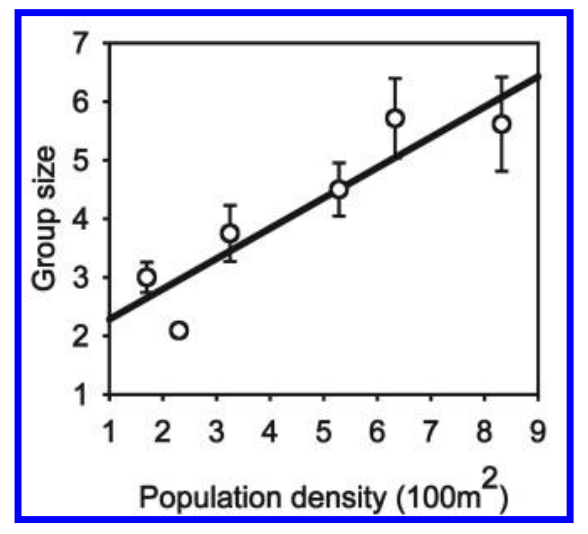

Figure 4: Relationship between subpopulation density and mean haremic group size (including one male; $\pm \mathrm{SE}$ ). 
4). In all subpopulations, every male (pooled $n=55$ ) encountered and observed was found to be defending at least one female, and there was only ever one male per group (i.e., males had discrete territories in which the females resided, and there were no bachelors or roaming males found). In addition, the male was always the largest haremic group member, consistent with the size-advantage model for protogynous sex change (see also Walker and McCormick 2009).

We stripped the eggs from females $(n=124)$ to determine daily egg production during spawning periods. Females were found to start producing mature eggs at 58$\mathrm{mm} \mathrm{TL}$, and daily egg production during spawning periods was found to increase linearly with body size thereafter $\left(\right.$ eggs day $^{-1}=37.334 \mathrm{TL}-2,053 ; r^{2}=0.3 ; F_{1,123}=43.6$, $P<.01$ ). From the observational data, experimental monogamous females were found to spawn $10.42 \pm 3.8 \mathrm{SE}$ times per month, and monthly spawning frequency was independent of body size (OLS regression; $F_{1,18}=3.43$, $P=.08)$. Mean female spawning frequency per month (FSF) among the subset of natural social groups was found to be similar to the experimental monogamous spawning frequency up until a group size of five (i.e., four females per male), after which point FSF declined hyperbolically $\left(\mathrm{FSF}_{(\mathrm{GS} \geq 4)}\right.$ month $^{-1}=(22.883 \times 4.499) /(22.883+\mathrm{GS}) ; r^{2}=$ $0.8 ; F_{1,2}=27.57, P=.034$; fig. $5 \mathrm{~A}$ ). Fertilization rate (FR) was found to slightly but significantly decline with social group size (including the male; $\mathrm{FR}=-0.0033 \mathrm{GS}+$ $\left.0.9847 ; r^{2}=0.3 ; F_{1,12}=5.18, P=.042\right)$.

Information on group-specific individual body sizes, daily size-based egg production, group size-based female monthly spawning rate, and fertilization rate was used to calculate group-specific PCF. The observed PCF by group size data were best explained by the Monte Carlo model that incorporated the protogyny sex-change rule. Iterations of $M_{\max }$ returned a best-fit $M_{\max }$ value of 52,594 eggs per month (SS $=63,286,881$ ), compared to the analytical model (which is insensitive to the sex-change rule), which returned a best-fit $M_{\max }$ value of 53,219 eggs per month $(S S=66,464,844$; fig. $5 B$ ). Importantly, data confirm that the protogyny sex-change rule results in lower PCF values at small group sizes (i.e., monogamous pairs) compared to those expected from a shift in sex ratio alone; the Allee effect in fecundity for Parapercis cylindrica is the result of both a density-dependent socially facilitated shift in sex ratio toward increased female function and a corresponding increase in mean and maximum female size. Note, however, that the analytical model (i.e., sex ratio) explains most of the variance in PCF (fig. $5 B$ ).

The employed analytical model differs from the Monte Carlo model in that the former predicts the sex ratio effect only (on the basis of mean female fecundity), while the latter incorporates the sex-change rule and its effect on

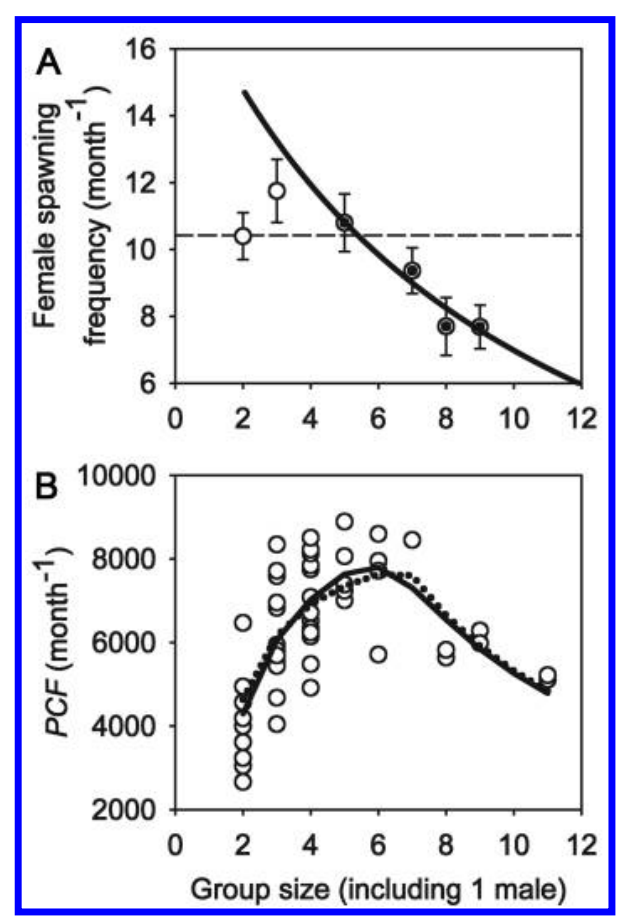

Figure 5: $A$, Relationship between group size and mean female monthly spawning frequency $( \pm \mathrm{SE})$ including the experimental monogamous pairs. Filled data points are those fitted to the hyperbolic decay function. $B$, Estimated per capita fecundity (PCF) with best-fit analytical model trajectory (dotted line) and best-fit Monte Carlo model trajectory (solid line).

group-specific female body sizes and subsequent individual egg production. The predicted PCF versus GS relationship differs between these two models because making the largest group member "male" has a greater effect on the female body size distribution (and thus egg production) in small groups than in large groups. While the difference in predicted group-specific PCF between the two models was quite low, the Monte Carlo model should nonetheless be considered in future studies. This is because the difference between the analytical PCF prediction and the Monte Carlo PCF prediction will increase when the relationship between female body size and egg production is nonlinear (see "The Model").

In polygynous sex-changing fishes, sex ratio in local groups is frequently adjusted so that there is generally only one male, who tends to be the largest individual (e.g., Moyer 1990; Shpigel and Fishelson 1991; Lutnesky 1994; Walker and McCormick 2009; see also Shapiro 1984; Warner 1988; Ross 1990; Munday et al. 2006). This flexible sex-determination strategy can be explained by sexual selection acting on large male body size and the subsequent differential size-based fecundity potentials of females and males (i.e., the SAH; Warner 1975, 1984a, 1984b, 1988; 
Munday et al. 2006; Walker and McCormick 2009). Because groups are constrained to have a male, as GS decreases, mean female body size also decreases, and the overall proportion of males in the population increases. This reduces the reproductive potential of the population (by up to 50\%) because fewer eggs are produced. Central to this phenomenon is the tendency of reef fishes to develop discrete home ranges or territories (Sale 1980); either reduced population density or increased habitat fragmentation reduces GS in site-attached fishes, driving a shift from polygyny to monogamy in the mating system and a balancing of the sex ratio (via sex change; often referred to as facultative monogamy; hawkfishes: Donaldson 1989, 1990; angelfishes: Moyer 1990; butterflyfishes: Hourigan 1989; groupers: Shpigel and Fishelson 1991; triggerfishes: Fricke 1980; Ishihara and Kuwamura 1996).

In essence, fragmented and low-density populations contain a large number of males that would otherwise be functioning as female. At present, sperm limitation is seen as a major concern for the resilience of commercially exploited protogynous taxa (Adams et al. 2002; Alonzo and Mangel 2004, 2005). This is because fishers tend to remove the largest individuals from the population, which are typically male. However, sperm limitation may be the first stage of a two-stage process in the decline of exploited protogynous stocks. For example, evidence suggests that locations open to fishing often harbor protogynous fish populations with a greater proportion of small males and transitional individuals (those in the process of sex change) compared to locations closed to fishing (Adams et al. 2002). This may reflect a reduced potential for polygyny, reduced sex-change suppression by males because of reduced behavioral encounter rates, and, subsequently, greater rates of sex change from female to male. If males are capable of producing more offspring than females, then overcompensation in sex-change frequency can only diminish PCF.

It is important to emphasize, however, that the sex ratio-based Allee effect does not translate into a higher extinction risk for sex-changers compared to gonochores with fixed, equal sex ratios; in fact, the contrary is true. Gonochores with a fixed, equal sex ratio bear the full cost of producing males irrespective of density, such that gonochore PCF can only be equal to sex-changer PCF (i.e., at low density, when sex-changers are forming monogamous pairs) or less than sex-changer PCF (i.e., at high density, when sex-changers are forming polygynous groups). Thus, considering two populations, one composed of sexchangers and the other of gonochores, and assuming a negligible cost of sex change, sex-changers will experience a productivity boost with an increase in density whenever the overall per capita population growth rate is positive. Moreover, should negative per capita population growth rate be experienced at low population density (i.e., when a critical density threshold is present), then our equivalent hypothetical gonochore population simply cannot persist. In essence, a sex-changer population can occupy demographic niches that are unavailable to the equivalent gonochore population, so long as the sex-changer population (or a source subpopulation) stays above the critical threshold density. In this way, sex-changers may be more resistant to short-term local declines in overall mortality rate or fecundity - whether naturally or anthropogenically induced-thereby providing greater resilience to reef fish communities in general.

Protogynous hermaphroditism is common among reef fishes and occurs in many commercially exploited taxa (Thresher 1984; Warner 1984b; Alonzo and Mangel 2004, 2005; Munday et al. 2006). In fact, protogynous hermaphroditism is the norm for a number of reef fish families (Thresher 1984; Sadovy de Mitcheson and Liu 2008). A recent review of the literature suggests that at least 70 tropical reef fishes may meet the basic prerequisites for a sex ratio-based Allee effect (i.e., males are more fecund than females, and female sex ratio bias initially increases with population density and group size; Walker and McCormick 2009). Our study suggests that habitat fragmentation and reduced population density may have a greater impact on the productivity of these fishes, and consequently the broader tropical reef community, than currently appreciated. However, our study suggests that the implementation of marine protected areas (MPAs; i.e., areas closed to human activity and fishing) is likely to have a greater positive effect on protogynous fish stocks and community stability than the implementation of fishing quotas. MPAs allow the preservation of high-quality, continuous habitat types and high-density populations to maximize polygyny and subsequent productivity and source-sink potential. By contrast, fishing quotas will encourage fishers to focus on high-density populations so as to maximize fishing efficiency, leading to fragmented populations, higher rates of sex change, and reduced productivity and population resilience.

While sex ratio-based Allee effects are likely to be most common in sex-changers (because of the extremity and frequency of sex ratio adjustment), sex change is not a fundamental requirement for the Allee effect to occur. So long as polygyny can be realized, density dependence in offspring sex ratio adjustment toward the less fecund sex (usually the female) will also lead to an Allee effect. A number of insects, reptiles, birds, and mammals are known to adjust the sex ratio of their young in response to local environmental conditions (Hamilton 1969; Trivers and Willard 1973; Werren 1980; Charnov 1982; West et al. 2000; Wade et al. 2003; Reece et al. 2008). The results of this study may therefore be applicable to a wide variety 
of taxa and population and community types. Assessment of how sex ratio-based positive density dependence alters the outcome of population and community models may be a fruitful avenue for future research.

\section{Acknowledgments}

We thank C. Chustz, A. Frisch, J. Maddams, C. Ryen, M. Shaw, and the staff of Lizard Island Research Station for their dedicated assistance in the field. We also thank P. Munday, R. Warner, and two anonymous reviewers for providing valuable comments on an earlier draft of the manuscript. Research was carried out under permit from the Great Barrier Reef Marine Park Authority and in ac. cordance with James Cook University ethics guidelines. Research was funded by a Lizard Island Doctoral Fellow. ship (Australian Museum) and a James Cook University Post Graduate Merit Research grant awarded to S.P.W.W. and by the Australian Research Council Centre of Excellence for Coral Reef Studies, James Cook University.

\section{Literature Cited}

$\rightarrow$ Adams, S., B. D. Mapstone, G. R. Russ, and C. R. Davies. 2002. Geographic variation in the sex ratio, sex specific size, and age structure of Plectropomus leopardus (Serranidae) between reefs open and closed to fishing on the Great Barrier Reef. Canadian Journal of Fisheries and Aquatic Sciences 57:1448-1458.

Allee, W. C. 1931. Animal aggregations, a study in general sociology. University of Chicago Press, Chicago.

Alonzo, S. H., and M. Mangel. 2004. Size-selective fisheries, sperm limitation and spawning per recruit in sex-changing fish. Fisheries Bulletin 102:1-13.

- 2005. Sex-change rules, stock dynamics, and the performance of spawning-per-recruit measures in protogynous stocks. Fisheries Bulletin 103:229-245.

$\rightarrow$ Berec, L., D. S. Biukal, and M. Berec. 2001. Linking the Allee effect, sexual reproduction, and temperature-dependent sex determination via spatial dynamics. American Naturalist 157:217-230.

Charnov, E. L. 1982. The theory of sex allocation. Princeton University Press, Princeton, NJ.

$\rightarrow$ Courchamp, F., T. Clutton-Brock, and B. Grenfell. 1999. Inverse density dependence and the Allee effect. Trends in Ecology \& Evolution 14:405-410.

Courchamp, F., L. Berec, and J. Gascoigne. 2008. Allee effects ir $\rightarrow$ ecology and conservation. Oxford University Press, New York.

$\rightarrow$ Davis, H. G., C. M. Taylor, G. Lambrinos, and D. Strong. 2004. Pollen limitation causes an Allee effect in a wind-pollinated invasive grass (Spartina alterniflora). Proceedings of the National Academy of Sciences of the USA 101:13804-13807.

$\rightarrow$ De Roos, A. M., and L. Persson. 2002. Size-dependent life-histor; traits promote catastrophic collapses of top predators. Proceedings of the National Academy of Sciences of the USA 99:12907-12912.

$\rightarrow$ Donaldson, T. J. 1989. Facultative monogamy in obligate coral $\rightarrow$ dwelling hawkfishes (Cirrhitidae). Environmental Biology of Fishes 26:295-302.
Pacific hawkfishes (Cirrhitidae). Japanese Journal of Ichthyology 36:439-457.

Ehrlich, P. R., and J. Roughgarden. 1987. The science of ecology. Macmillan, New York.

$\rightarrow$ Fricke, H. W. 1980. Mating systems, maternal and biparental care in triggerfish (Balistidae). Zeitschrift für Tierpsychologie 53:105-122.

$\rightarrow$ Frisch, A. J., S. P. W. Walker, M. I. McCormick, and T. K. SolomonLane. 2007. Regulation of protogynous sex change by competition between corticosteroids and androgens: an experimental test using sandperch, Parapercis cylindrica. Hormones and Behavior 52:540545.

Ghiselin, M. T. 1969. The evolution of hermaphroditism among animals. Quarterly Review of Biology 44:189-208.

Groom, M. J. 1998. Allee effects limit population viability of an annual plant. American Naturalist 151:487-496.

Hamilton, W. D. 1969. Extraordinary sex ratios. Science 156:477488.

Hourigan, T. F. 1989. Environmental determinants of butterflyfish social systems. Environmental Biology of Fishes 25:61-78.

$\rightarrow$ Hutchings, J. A. 2000. Collapse and recovery of marine fishes. Nature 406:882-885.

$\rightarrow$ Ishihara, M., and T. Kuwamura. 1996. Bigamy or monogamy with maternal egg care in the triggerfish, Sufflamen chrysopterus. Ichthyology Research 43:307-313.

$\rightarrow$ Kindvall, O., K. Vessby, A. Berggren, and G. Hartman. 1998. Individual mobility prevents an Allee effect in sparse populations of the bush cricket Metrioptera roeseli: an experimental study. Oikos 81:449-457.

Levitan, D. R., M. A. Sewell, and F. Chia. 1992. How distribution and abundance influence fertilization success in the sea urchin Strongylocentrotus franciscanus. Ecology 73:248-254.

$\rightarrow$ Liermann, M., and R. Hilborn. 1997. Depensation in fish stocks: a hierarchic Bayesian meta-analysis. Canadian Journal of Fisheries and Aquatic Sciences 54:1976-1984.

$\rightarrow$ Lutnesky, M. F. 1994. Density-dependent protogynous sex change in territorial-haremic fishes: models and evidence. Behavioral Ecology 5:375-383.

$\rightarrow$ Lutnesky, M. F., and R. K. Kosaki. 1995. Female-female competition in a coral reef fish and a test of the temporal threshold model of polygynous mating. American Naturalist 146:832-847.

Marconato, A., V. Tessari, and G. Marin. 1995. The mating system of Xyrichthys novacula: sperm economy and fertilization success. Journal of Fish Biology 47:292-301.

$\rightarrow$ Marconato, A., D. Y. Shapiro, C. W. Petersen, R. R. Warner, and T. Yoshikawa. 1997. Methodological analysis of fertilization rate in the bluehead wrasse Thalassoma bifasciatum: pair versus group spawns. Marine Ecology Progress Series 161:61-70.

Morris, D. W. 2002. Measuring the Allee effect: positive density dependence in small mammals. Ecology 83:14-20.

Moyer, J. T. 1990. Social and reproductive behavior of Chaetodontoplus mesoleucus (Pomacanthidae) at Bantayan Island, Philippines, with notes on pomacanthid relationships. Japanese Journal of Ichthyology 36:459-467.

Munday, P. L., P. Buston, and R. Warner. 2006. Diversity and flexibility of sex-change strategies in animals. Trends in Ecology \& Evolution 21:89-95.

$\rightarrow$ Myers, R. A., N. J. Barrowman, J. A. Hutchings, and A. A. Rosenberg. 1995. Population dynamics of exploited fish stocks at low densities. Science 269:1106-1108.

. 1990. Reproductive behavior and social organization of somı $\rightarrow$ Paddack, M. J., J. D. Reynolds, C. Aguilar, R. S. Appeldoorn, J. Beets, 
E. W. Burkett, P. M. Chittaro, et al. 2009. Recent region-wide declines in Caribbean reef fish abundance. Current Biology 19: 590-595.

Petersen, C. W., and E. A. Fischer. 1986. Mating system of the hermaphroditic coral-reef fish, Serranus baldwini. Behavioral Ecolog, and Sociobiology 19:171-178.

R Development Core Team. 2009. R: a language and environmen. for statistical computing. R Foundation for Statistical Computing, Vienna. http://www.r-project.org.

Randall, J. E., G. R. Allen, and R. C. Steene. 1997. Fishes of the Great Barrier Reef and Coral Sea. University of Hawaii Press, Honolulu.

$\rightarrow$ Reece, S. E., D. R. Drew, and A. Gardner. 2008. Sex ratio adjustment and kin discrimination in malaria parasites. Nature 453:609-614.

$\rightarrow$ Robertson, D. R. 1972. Social control of sex reversal in a coral-ree fish. Science 177:1007-1009.

$\rightarrow$ Ross, R. M. 1990. The evolution of sex-change mechanisms in fishes. Environmental Biology of Fishes 29:81-93.

$\rightarrow$ Sadovy de Mitcheson, Y., and M. Liu. 2008. Functional hermaphroditism in teleosts. Fish and Fisheries 9:1-43.

$\rightarrow$ Sæther, B.-E., T. H. Ringsby, and E. Røskaft. 1996. Life history variation, population processes and priorities in species conservation: towards a reunion of research paradigms. Oikos 77:217-226.

$\rightarrow$ Sale, P. F. 1980. Assemblages of fish on patch reefs: predictable or unpredictable? Environmental Biology of Fishes 5:243-249.

Shapiro, D. Y. 1984. Sex reversal and sociodemographic processes in coral reef fishes. Pages 103-118 in G. W. Potts and R. J. Wootton eds. Fish reproduction, strategies and tactics. Academic Press, London.

$\rightarrow$ Shapiro, D. Y., A. Marconato, and T. Yoshikawa. 1994. Sperm economy in a coral reef fish, Thalassoma bifaciatum. Ecology 75:13341344.

$\rightarrow$ Shpigel, M., and L. Fishelson. 1991. Territoriality and associated behaviour in three species of the genus Cephalopholis (Pisces: Ser ranidae) in the Gulf of Aqaba, Red Sea. Journal of Fish Biology 38:887-896.

$\rightarrow$ Stephens, P. A., and W. J. Sutherland. 1999. Consequences of the Allee effect for behaviour, ecology and conservation. Trends in Ecology \& Evolution 14:401-405.

$\rightarrow$ Stephens, P. A., W. J. Sutherland, and R. P. Freckleton. 1999. What is the Allee effect? Oikos 87:185-190.
Stroud, G. J. 1982. The taxonomy and biology of fishes from the genus Parapercis. PhD diss. James Cook University, Townsville.

Thresher, R. E. 1984. Reproduction in reef fishes. TFH, Neptune City, NJ.

Trivers, R. L., and D. E. Willard. 1973. Natural selection of parental ability to vary the sex ratio of offspring. Science 179:90-92.

Wade, M. J., S. M. Shuster, and J. P. Demuth. 2003. Sexual selection favors female-biased sex ratios: the balance between the opposing forces of sex-ratio selection and sexual selection. American Naturalist 162:403-414.

Walker, S. P. W., and M. I. McCormick. 2004. Otolith-check formation and accelerated growth associated with sex change in a haremic reef fish. Marine Ecology Progress Series 266:201-212.

$\rightarrow-2009$. Sexual selection explains sex-specific growth plasticity and positive allometry for sexual size dimorphism in a reef fish. Proceedings of the Royal Society B: Biological Sciences 276:33353343.

Warner, R. R. 1975. The adaptive significance of hermaphroditism in animals. American Naturalist 109:61-82.

$\rightarrow-1984 a$. Deferred reproduction as a response to sexual selection in a coral reef fish: a test of the life historical consequences. Evolution 38:148-162.

1984b. Mating behavior and hermaphroditism in coral reef fishes. American Scientist 72:128-136.

$\rightarrow-1988$. Sex change and the size advantage model. Trends in Ecology \& Evolution 3:133-136.

$\rightarrow$ Warner, R. R., D. Y. Shapiro, A. Marcanato, and C. W. Petersen. 1995. Sexual conflict: males with highest mating success convey the lowest fertilisation benefits to females. Proceedings of the Royal Society B: Biological Sciences 262:135-139.

$\rightarrow$ Wells, H., E. G. Strauss, M. A. Rutter, and P. H. Wells. 1998. Mate location, population growth and species extinction. Biological Conservation 86:317-324.

$\rightarrow$ Werren, J. H. 1980. Sex ratio adaptations to local mate competition in a parasitic wasp. Science 208:1157-1159.

$\rightarrow$ West, S. A., E. A. Herre, and B. C. Sheldon. 2000. The benefit of allocating sex. Science 290:288-290.

Associate Editor: Jukka Jokela Editor: Mark A. McPeek

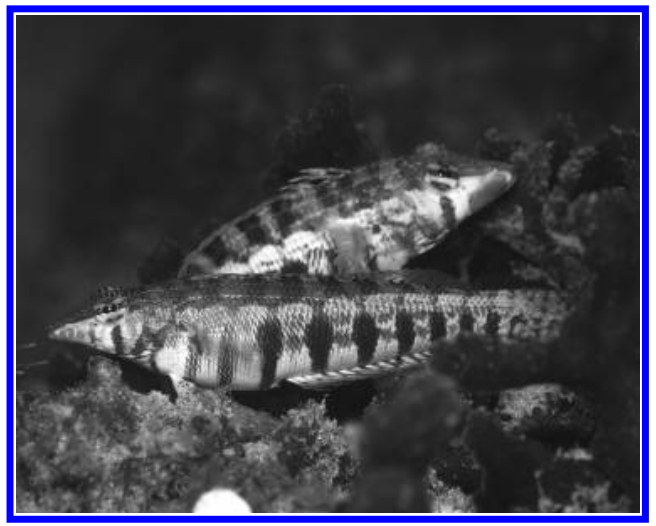

The model species Parapercis cylindrica: female appears in the front. 